\title{
INTERFERÊNCIAS HUMANAS EM BENS DA NATUREZA E DA CULTURA
}

\author{
Américo Pellegrini Filho*
}

\begin{abstract}
RESUMO: Bens naturais e bens culturais se incluem entre os maiores atrativos turísticos; preservá-los deve ser uma conseqüência lógica e uma preocupaçāo do "marketing" turístico. O artigo discute - com exemplos - a preservação ativa, apontando a necessidade de se criarem experiências brasileiras válidas em turismo eco-cultural, privilegiando-se o turismo brando que minimiza interferências prejudiciais.
\end{abstract}

UNITERMOS: Meio Ambiente: bens da natureza; bens culturais: ecologia; ecoturismo. Ecoturismo: educação ambiental; planejamento.

\begin{abstract}
Material and cultural goods are among the highest touristic attractions; to preserve it must be a logic consequence and a worry of the touristic market. The article discusses "with examples" the active preservation, pointing out the need to create Brazilian experience which are valid for eco-cultural tourism, jeopardizing soft tourism which minimizes damagic interferences.
\end{abstract}

KEY WORDS: Environment: nature goods; cultural goods; ecology. Ecotourism: environmental education; planning.

\section{INTRODUÇÃO}

Com a conscientização de razões válidas para a preservação de bens da natureza e da cultura, variadas interferências humanas nesse patrimônio social acabam ocasionando intermináveis discussões. Às vezes, a própria preservação pura e simples pode caracterizar-se como interferência no processo formação/vida/envelhecimento/morte de um bosque, de um ecossistema centralizado num lago, de um bairro histórico, de uma fortaleza que se tornou anacrônica, e assim por diante.

$\left(^{*}\right)$ Professor Livre-Docente do Curso de Turismo do Departamento de Relações Públicas, Propaganda e Turismo da ECA/USP.

End. corresp.: ECA/USP - Depto. de Relações Públicas, Propaganda e Turismo Cidade Universitária "Armando de Salles Oliveira" - Av. Prof. Lúcio Martins Rodrigues, 443 - 05508-900 - São Paulo - SP - Brasil. 
Múltiplos interesses entram em jogo, o que explica a freqüente falta de consenso quanto à solução ideal. Nestas linhas, estudam-se aspectos genéricos de interferências antrópicas em pontos da natureza e da cultura que adquiriram excepcional importância. ${ }^{*}$

\section{BENS DA NATUREZA E CULTURAIS}

\subsection{Bens da Natureza}

Deixando de lado posições de ecologistas radicais (zombeteiramente chamados "ecoxiitas" e "ecochatos"), podem-se considerar muitas possibilidades de aproveitamento de recursos da natureza, de tal modo que não sejam arruinados e, ao mesmo tempo, passem a ter novas utilidades atendendo a situações contemporâneas. Diversos países (Estados Unidos, Costa Rica, México, Equador, Espanha, África do Sul, Quênia e outros) vêm realizando experiências positivas quanto) ao uso de seus parques nacionais, à administraçāo de praias com beleza excepcional frente ao fluxo de usuários, ao controle de áreas de caça e pesca, a locais destinados a acampamento, a reservas florestais dispondo de pequenas áreas para visitaçāo, ao melhor aproveitamento de hidrovias etc. $\mathrm{O}$ zelo de entidades ambientalistas serve como garantia para se evitarem perdas, o que não dispensa planejamento rigoroso, verificaçāo de custos/benefícios, critérios para minimizar impactos. São itens enquadráveis na abrangência do desenvolvimento sustentado.

O caso de cavernas é interessante. Dizem que "uma caverna sem visitação, sem uso, é como se não existisse". A partir daí, se formam "caravanas turísticas" para apreciar a obra milenar da natureza; e os intempestivos visitantes não se acanham em "levar um troféu", certamente algum pedaço de estalactite (lá do alto) ou de estalagmite (aqui embaixo, mais próximo das mãos), como prova da viagem ou, não raro, perdendo-o antes de voltar para casa...

A famosa caverna de Lascaux, na França, é um dos muitos exemplos de interferência humana em bens da natureza. Formado o grande e constante fluxo turístico, observou-se que o frágil ecossistema interno de Lascaux estava sofrendo mudanças que influiam nas preciosas

(*) Definiçōes e recomendaçōes formuladas em encontros internacionais promovidos pela UNESCO, $\mathrm{cm}$ especial a "Convenção para a Proteção do Patrimônio Mundial Cultural", da $17^{\text {a }}$ Reuniāo da Unesco, Paris, 1972. ${ }^{22}$ pinturas rupestres com cerca de 17 mil anos de vida. Fechou-se a caverna à visitaçāo, e planejou-se a construção da Lascaux II, uma réplica feita com critérios científicos, perto de 2.500 metros de distância da original. Em 1986 foi reiniciada a visitação, evidentemente na Lascaux II, e determinou-se que a original pode receber apenas 5 visitantes por semana, público selecionado logo se vê.

Mas nem sempre é possível adotar solução desse tipo. Muitas outras cavernas, em muitos países, receberam equipamentos básicos e indispensáveis (iluminação, corrimãos, pisos etc.) para a visitação, o que constitui caminho para o impacto ambiental em seu interior. No Brasil, há vários casos de cavidades naturais que agora só têm interesse como atrativos turísticos, uma vez que suas salas, seus corredores, seus precipitados, até sua temperatura acham-se alterados. Exemplo é a Caverna do Diabo (Eldorado Paulista - São Paulo), uma das duas centenas de cavernas do sul paulista, que teve seu interior acrescido de escadas de concreto com corrimãos de aço, sistema de som, sistema de iluminaçāo e outros recursos, instalados mediante projeto de boa qualidade. Outro exemplo é a Gruta de Ubajara (Parque Nacional de Ubajara, oeste do Ceará), com sistema de iluminação resultante de projeto infeliz (tubulações à vista, holofotes mal disfarçados), e com inúmeras pichações de visitantes ignorantes da importância da cavidade natural, comprometendo-a irremediavelmente; o governo estadual instalou também, no entorno, um custoso teleférico, deixando de lado a possibilidade de o turista usufruir a linda paisagem da serra de Ibiapaba, por terra.

Voltando ao caso das cavernas do sul paulista - agrupadas no PETAR-Parque Estadual do Alto Ribeira - percebe-se que requerem um macroprojeto que talvez deva liberar esta ou aquela cavidade para visitaçāo, e estabelecer rigoroso controle de visitas para outras. Chega a ser desastroso o que já aconteceu com a Gruta de Santana, com as dilapidações sofridas nas décadas de 1970/90. Evidentemente, tudo isso deve basear-se numa política de uso sustentável de bens da natureza.

Outro caso é o das passarelas de concreto armado construídas junto a quedas d'água no lado brasileiro das Cataratas do Iguaçu (Parque Nacional do Iguaçu, Paraná) e na praia do Forte junto à entrada do Forte dos Reis Magos (Natal - Rio Grande do Norte). Até onde é válido acrescentar esses artefatos a bens da natureza e da cultura, sabendo-se que interferem enormemente na própria fruição desses atrativos? A resposta é difícil e cheia de conflitos. 


\subsection{Bens Culturais}

Se alguns tipos de recursos naturais não oferecem muitas alternativas para adequação e uso, levando muitas vezes a impactos ambientais que entretanto podem ser minimizados, o caso de artefatos humanos é semelhante, ocorrendo diferentes fatores de interferência: especulação imobiliária, ganância de comerciantes de antiguidades e outros intermediários, idiossincrasia de colecionadores, ignorância a respeito de significados do bem cultural e assim por diante. Uma lista de perdas de bens culturais, no Brasil, seria quilométrica; aliás, o mesmo acontece com outros países, diga-se de passagem.

Se ainda ocorrem destruições, acontecem também tentativas de conciliar interesses econômicos com as recomendações em favor da preservação de manifestações materiais ou espirituais. É o caso do arranha-céu construído na área que tinha sido quintal ( $a h$, os amplos $e$ arborizados quintais de antigamente...) do imóvel n. ${ }^{\circ} 37$ da avenida Paulista (São Paulo-SP), o chamado "Casarão das Rosas": dispondo de aprovação do CONDEPHAAT - Conselho de Defesa do Patrimônio Histórico, Artístico, Arqueológico e Turístico do Estado - o projeto de um moderno espigão - com premeditada e expressiva fachada em acrílico esverdeado - foi montado tendo por base o compromisso de restauração e manutenção do "Casarão das Rosas", utilizado pela Secretaria da Cultura para atividades especialmente na área de artes plásticas. Considera-se, então, que a cultura ganhou um espaço, enquanto os proprietários do imóvel e os empresários do setor imobiliário também ganharam, evitando-se a destruição pura e simples do imóvel de valor incomum e tombado a nível estadual. Outro exemplo é o prédio construído na esquina das ruas 9 de Março e 15 de Novembro (Joinville - Santa Catarina): foi conservado um sobrado antigo, e o novo edifício inserido no seu corpo, "esquisitamente". Mais outro exemplo da já citada e valorizada avenida Paulista é o da mansão Matarazzo: após "vai-vens" quanto à sua preservação, incluindo tentativa de dinamitação por parte dos proprietários desejosos de vendê-la para construção de arranha-céu (final da década de 1980 e inícios da seguinte), chegou-se a um projeto que conserva o imóvel dando-lhe a particular função de ser o saguão nobre de outro espigão. Tratam-se de buscas de conciliação - às vezes mais felizes, outras vezes menos felizes - de imóveis que adquiriram um significado especial, e que por isso merecem ser preservados, mas também atendendo a interesses econômicos.
Outro caminho, defendido por muitos estudiosos e até recomendado por órgãos especializados, é o de reciclar determinados bens culturais, de modo que possam atender às necessidades da vida contemporânea, sem perda de suas características originais básicas. Um sobrado senhorial ou um humilde conjunto de casinhas, uma sede de fazenda ou uma fortaleza, um bairro histórico e semelhantes podem passar pelas obras de restauro, de adaptações e outras, a fim de abrigar centros culturais, museus, hóteis, restaurantes (quem sabe de culinária regional, associando outros traços culturais), albergue para estudantes, outros serviços de atendimento ao turismo, também entidades ou serviços de atendimento à comunidade local, como escolas, biliotecas públicas, centros de saúde, órgãos de administração pública, sedes de entidades culturais locais etc. Em Bonn, a casa onde nasceu e morou Ludwing van Beethoven foi transformada no Museu Casa de Beethoven; em Sintra, o Palácio Seteais (originalmente do comerciante holandês Gildmeester, século XVIII, com modificações posteriores) foi reciclado para hotel de luxo; em Paris, a estação ferroviária d'Orsay foi reformada para abrigar o Museu d'Orsay, que na verdade é um centro cultural (auditório, biblioteca, livraria, restaurantes, salas de projeções, sala de concertos, sala para atividades infantis etc.); em Havana, o Palácio Residencial, que foi moradia oficial de presidentes republicanos antes da revolução de 1959, abriga o Museu da Revolução; e muitos outros exemplos.

No Brasil também são muitos os exemplos: residências assobradadas e térreas no Pátio de São Pedro (Recife - Pernambuco) reformadas para abrigar lojas de artesanato, bares, livraria, restaurante e outros serviços; residências - no bairro do Palorinho (Salvador - Bahia) - que passou por acentuado processo de depreciação - restauradas e passando a ter outras funções, como as de restaurante, museu, sede da regional do Instituto Brasileiro do Patrimônio Cultural, lojas de artesanato e outras; sobrados residencias do ciclo da borracha no bairro do Comércio (Belém - Pará), reformados para funcionamento de agências bancárias; sobrado residencial na avenida Paulista, (São Paulo - SP), reformado para abrigar um restaurante da rede MacDonalds; conventos e outras construções de função religiosa transformados em Museus de Arte Sacra em Salvador, São Paulo, Santos, Itu, Recife, Olinda, Maceió, João Pessoa, Goiás, Parati; residência do imigrante Ottokar Doerfell (Joinville), transformado em Museu de Arte; construção assobradada onde funcionou a delegacia de Polícia em Tietê, abrigando o Museu Histórico e Pedagógico Cornélio Pires; o Palácio do Catete (Rio de Janeiro), ex-sede do Governo Federal, que passou abrigar o Museu da República; e outros.

Feita a reciclagem do imóvel, resta um problema: a manutenção das novas funções, conforme planejado, ao mesmo tempo em que não se provoquem prejuízos para o bem cultural reaproveitado. 


\section{RELAÇÕES COM O TURISMO}

Modernos estudos de turismo acentuam a necessidade de se atentar para o perigo dos comunidades receptoras ou populações endógenas não receberem benefícios, e até serem prejudicadas. É inegável que aos empresários do setor e aos dirigentes de órgãos públicos de turismo cabe a função de controlar todos os aspectos do marketing do setor, dando o devido realce para as vantagens que podem advir para a comunidade receptora ${ }^{14}$. A respeito da problemática custo/benefício de bens naturais e culturais frente ao turismo, é sempre oportuno lembrar as colocações de Pierre Eugene sobre a evolução das relações entre turismo e ambiente, caracterizadas por quatro fases:

a) primeiramente, verificam-se fluxos turísticos limitados, e tais atividades funcionam como reveladoras dos atrativos turísticos, como se fosse um descobrimento para gozo do visitante;

b) a segunda fase é marcada pelo turismo de massa, com grande concentração de visitantes, no tempo e no espaço; ocorrem modificações e degradação dos núcleos receptivos, como conseqüência de equipamentos superdimensionados, do aumento rápido de poluentes convencionais e o surgimento de novos fatores de poluição, de prejuízos para as qualidades naturais do local; esta é a fase na qual "o turismo mata o turismo", por motivo dos próprios exageros cometidos;

c) a terceira fase é a da reparação: as fontes de poluição recebem certo controle, ainda que certos poluentes tenham efeitos irreversíveis;

d) finalmente, a quarta fase é a de reconciliação: a variável meio ambiente passa a ser parte integrante do projeto de operação turística, advindo preocupações com estudos de impacto ambiental. ${ }^{9}$

Nas palavras desse autor:

Nesta ótica, há o empenho de se inı'cntariar as qualidades naturais de um local e de tomar as medidas que se impóem para consen'ar o potencial atrativo. De se realizar um "balanço ecológico" para se estipular as normas que serão respeitadas. De desum "balanço ecologico "para se estipular as normas que
truidor, o turismo passa entáo a defensor do ambiente."

(*) Ver também o artigo "Entre jardin d'Eden et de raison". onde o autor tece consideraçōes sobre opiniōes contraditorias e opostas a respeito do meio ambiente. afir mando que não existe uma noção única sobre o assunto. Na verdade. diz. devem ser confrontadas quatro concep̧̧ōes: individualista apropriativa; protecionista comunitária, que propōe gestāo coletiva: individual liberal que privilegia a responsabilidade de cada um; coletiva orientada para a preservaçāo de grandes equilíbrios por meio de açōes públicas. ${ }^{1.5}$
Tais observações, baseadas na realidade européia mas perfeitamente aplicáveis ao Brasil e a outros países, indica que o turismo em si pode vir a ser um fator de amparo e preservação ativa de bens da natureza - e, acrescente-se, da cultura. O maior problema reside no turismo de massa, que sobrecarrega enormemente determinados núcleos receptores, trazendo malefícios tanto para a população fixa tanto quanto para os próprios visitantes (doenças por causa da falta de saneamento básico, insuficiência no abastecimento de água, desabastecimento de gêneros alimentícios, filas, trânsito atravancado, aumento de violência urbana e assim por diante).

Uma conclusão óbvia logo salta aos olhos: a necessidade de se cuidar de planejamentos privilegiando o turismo suave, portanto proibindo a concentração de estruturas urbanas que levem a enormes fluxos turísticos. Evidentemente, ao menos em princípio, isso pode ir contra a ganância imobiliária e interesses empresariais e políticos. Todavia, trata-se de providência básica indispensável, a ser adotada urgentemente. Fluxos de visitantes adequados à capacidade de recepção constituem pré-requisito para chegar-se ao nível ótimo de fruição de bens naturais e culturais, bem como, afinal, para a própria qualidade de vida de turistas e da população endógena.

Sendo importante a responsabilidade social do turismo, a começar pela valorização da qualidade de vida da população receptora, evidentemente não devem ser esquecidos outros aspectos do marketing turístico: atender da melhor maneira o consumidor e suas expectativas sem causar impactos nos atrativos naturais e culturais, contribuir para a educação ambiental, ao mesmo tempo garantir lucros para a empresa; tratam-se de variáveis que, modernamente, devem ser consideradas em qualquer projeto de turismo* . Conciliar tais aspectos é o desafio de uma atividade empresarial que engatinha, no Brasil, e que aguarda decisões categóricas.

Se isso ocorre com o turismo de modo geral, especificamente com o ecoturismo - incrementado em função da valorização da ecologia especialmente na década de 1980 -, verifica-se que ele pode ser uma "faca de dois gumes", de maneira ainda mais acentuada:

a) estando o público consumidor devidamente alertado a respeito de suas responsabilidades frente à natureza que ele procura usufruir e por isso sabe evitar sua degradação, a atividade ecoturística será

(*) A responsabilidade social do setor de turismo, na vida moderna, é ressaltada por di versos autores. $1.7,8,12,13,20,24$ 
benéfica à preservação ativa* dos recursos naturais (e, por extensão, dos recursos culturais, ambos sempre muito interrelacionados);

b) se o consumidor não estiver consciente da necessidade de procedimentos adequados, então o ecoturismo será mais um lamentável fator de poluição, de desequilíbrio, de descaracterização, de destruição.

c) o planejador-operador de turismo deve incluir entre suas responsabilidades a de preservar os atrativos explorados.

Na realidade, ao estudioso e ao planejador de turismo não deve faltar a visão sistêmica do contexto sócio-econômico-cultural em que ele se insere.

Toda essa problemática converge para a formação de hábitos apropriados, constituindo outra área em que se deve criar experiência. A educação ambiental deve permear desde a escola primária até atividades sindicais, associativas etc., sem que se esqueçam segmentos adultos da população, trabalháveis através de campanhas em que o empresariado pode (e deve) colaborar e nas quais o poder de persuação de orgãos de comunicação social deve ser usado. A necessidade de educação ambiental, aliás, não implica necessidade de se criar mais uma disciplina no $1^{\circ}$ grau, mas sim reciclar professores já atuando no magistério de modo a lhes fornecer conteúdos programáticos a serem acrescentados em suas aulas, e também fornecer a alunos dos cursos de formação de professores os mesmos conteúdos. É um estado de espírito, aprendido e praticado no dia-a-dia, onde o turismo pode ajudar, e muito.

Percebe-se como tais assuntos constituem facetas de ampla problemática. Dentre essas facetas deve-se incluir a consciência de cida dania - no que o povo brasileiro năo parece ser bem dotado... - a qual implica mudança de mentalidade, exigindo tempo que variará em função da intensidade e do empenho com que as atividades forem desenvolvidas.

(*) Denomina-se "preservação ativa" à conservação de bens naturais e culturais. dan do-se-Ihes ao mesmo tempo uma função conveniente, com soluções adequadas ac desejado progresso: portanto. implica o uso adequado de atrativos da natureza e da cultura, minimizando o seu prejuízo e ou sua perda. A junçāo de dois tipos de recursos turísticos permite a conscientização do chamado turismo eco-cultural.

\section{CONSIDERAÇÕES FINAIS}

Tem sido exaustivamente repetido que, no Brasil, os governos não) têm dado ao setor de Turismo a importância que seria de se esperar, frente à potencialidade existente e frente à realidade mundial desse fenômeno que movimenta milhões de dólares. Quando tais circunstâncias são colocadas em conjunção com a necessidade de se preservarem bens da natureza e da cultura (conforme recomendações efetuadas em reuniões de caráter internacional), percebe-se facilmente a configuração de um lamentável quadro de perdas ao patrimônio nacional e de perda de oportunidades, no sentido de melhorar a qualidade de vida de segmentos populacionais endógenos e contribuir para a melhoria da situação econômico-financeira do País.

Mas há um longo caminho a ser percorrido por governantes, empresários, consumidores, técnicos especializados e mesmo a população em geral, para se obter a experiência e se tomarem as decisões mais adequadas, como outros países, inteligentemente, já conseguiram. As interferências humanas na natureza e na cultura podem ser minimizadas, e o irrefreável Turismo como fenômeno mundial pode ser um fator favorável, até porque sendo planejado e realizado com bom senso nãc: destrói os atrativos que o fazem "viver".

\section{BIBLIOGRAFIA}

1. ACERENZA, Miguel Ángel. Adıninistración del turismo - conceptualización organización. $2^{\mathrm{a}}$ ed., México, Trilhas, 1984.v.1.

2. BACAL, Sarah S. Turismo: dinâmica atual, posicionamento brasileiro, Turismo cm Análise São Paulo, v. 1, n. 1, p. 5-13, maio 1990

3. BOO, Elizabeth. Ecoturism: the potentials and pitfalls. Washington, World Wildife Fund, 1990, $2 \mathrm{v}$.

4. CARRAZZONI, M. Elisa. Guia dos bens tombados. Rio de Janeiro, Expressāo e cultura. 1980.

5. CLARKE, George L. Elements of ccologr: New York. John Wiley, 1954.

6. CONSERVACIÓN de los bienes culturales. Lausanne, UNESCO. 1969.

7. DAVDISON, Rob. Tourism. London. Pitman. 1989.

8. DIXON, John A.. \& SHERMAN. Paul B. Economics of protected areas. Ambio, Stockholm, v. 20, n. 2, abr. 1991

9. EUGENE. Pierre. Le tourisme - Destructeur ou protecteur de l'environment? Espaces. Paris, n. 48 , out. 1980

10. GEORGE, Pierre. O meio ambiente. S. Paulo. Difusāo Européia do Livro. 1973.

11. GONÇALVES. Carlos W. P. Os (des) caminhos do meio ambiente, S. Paulo. Contexto, 2. ed., 1990.

12. KEOGH, Brian. Public participation in community tourism planning. Annals of Tourism Research. New York, v. 17. n. 3, 1990

13. KRIPPENDORF, Jost. Les dev'oreurs de paysages. Lausanne, 24 Heures, 1977. 
14. Sociologia do turismo. Rio de Janeiro, Civilização Brasileira, 1989.

15. LASCOUMES, P. Entre jardin d'Eden et de raison. Libération, Paris, 8 abr.1992.

16. LEMOS, Carlos A. C. O que é patrimônio histórico. S. Paulo, Brasiliense, 1981.

17. MEDIO ambiente en la economía social de mercado. Buenos Aires. Fund. Konrad Adenauer/CIEDLA, 1990.

18. MINISSI, Franco. Consen'azione dei beni storico c ambicntali. Roma, De Luca. 1978.

19. MOLiNA, E. Sérgio. Turismo y ecología. México, Trillas, 1986.

20. MOYA, Ana. Crónica de eventos: Primeiras Jornadas Nacionales sobre Turismo de Aventura. Rev: Latinoamcricana de Turismo, Buenos Aires, v. 1, n. 1, 1991.

21. ODUM, Eugene. Ecologia. México, Continental. 1965.

22. PATRIMÔNIO CULTURAl.S. Paulo, FAU/SPHAN, 1974, 5 v.

23. PELLEGRINI FILHO, A. Problemática do património natural/cultural no Brasil, Turisino c̀n Análise. S. Paulo, v. 1, n. 1. p. 55-61, maio 1990.

24. QUINTĀO, Aylê S. F. Ecoturismo: uma alternativa do novo modelo de desenvolvimento. Brasil Florcstal, Brasília, v. 17, n. 69, 1990.

25. SHLÜTER. Regina G. El turismo internacional en América Latina. Rev: Latinoamericana de Turismo, Buenos Aires, v. 1, n. 1, jan. 1991.

26. SPHAN. Protcçào e revitalizaçào do patrimônio cultural no Brasil: uma trajetśria. Brasília, SPHAN, 1980. 